\title{
A Review of the Challenges Associated with the Diagnosis and Therapy of Primary Sclerosing Cholangitis
}

\author{
Mohammed Saadi, Christine Yu and Mohamed O. Othman \\ Department of Medicine, Division of Gastroenterology and Hepatology, Texas Tech University Health Science Center-Paul L. \\ Foster School of Medicine, El Paso, TX, USA
}

\begin{abstract}
Primary sclerosing cholangitis (PSC) is a chronic and progressive cholestatic liver disease that often leads to the development of cirrhosis. Complications of PSC include pruritus, fatigue, vitamin deficiencies, metabolic bone disease, dominant biliary strictures, gallstones, and hepatobiliary malignancies, most commonly cholangiocarcinoma (CCA). Despite the presumed autoimmune etiology of PSC, a clear benefit from immunosuppressive agents has not yet been established, and their use is limited by their side effects. Endoscopy is required in evaluation of biliary strictures in PSC to rule out the possibility of CCA. Liver transplantation is currently the only life-extending therapy for patients with end-stage disease. However, disease recurrence can be a source of morbidity and mortality as transplanted patients survive longer. Further studies are needed to develop an optimal therapeutic strategy for patients with PSC to decrease the incidence of complications of the disease, to decrease the need for transplantation, and to extend life expectancy.

(C) 2014 The Second Affiliated Hospital of Chongqing Medical University. Published by XIA \& HE Publishing Ltd. All rights reserved.
\end{abstract}

\section{Introduction}

Primary sclerosing cholangitis (PSC) is a chronic cholestatic liver disease that predominantly affects young males and has a reported prevalence of up to 16.2 per $100,000 .^{1}$ PSC is

Keywords: Cholangiocarcinoma; Cholestasis; Liver transplantation; Primary sclerosing cholangitis.

Abbreviations: ABBS, Atypical Biliary Brushing Score; ACR, acute cellular rejection; ANA, antinuclear antibodies; C-ANCA, cytoplasmic antineutrophil cytoplasmic antibodies; CCA, cholangiocarcinoma; CT, computed tomography; ERC, endoscopic retrograde cholangiography; EUS, endoscopic ultrasound; FISH, fluorescence in situ hybridization; FNA, fine needle aspiration; HLA, human leukocyte antigen; IBD, inflammatory bowel disease; IgG4, immunoglobulin G4 MRC, magnetic resonance cholangiography; NKG2D, natural killer group 2 , member D; p-ANCA, perinuclear antineutrophil cytoplasmic antibodies; PBC, primary biliary cirrhosis; $\mathrm{pCLE}$, probe-based confocal laser endomicroscopy; PNPLA3, palatin-like phospholipase-3; PSC, primary sclerosing cholangitis; SOC single operator cholangioscopy; SSC, secondary sclerosing cholangitis; UC, ulcerative colitis; UDCA, ursodeoxycholic acid; UNOS, United Network for Organ Sharing; US, ultrasound.

Received: 28 October 2013; Revised: 01 February 2014; Accepted: 04 February 2014

DOI of original article: 10.14218/JCTH.2013.00021.

Correspondence to: Mohamed O. Othman, Division of Gastroenterology, Department of Internal Medicine, Texas Tech University HSC, 4800 Alberta Avenue, EI Paso, TX 79905, USA. Tel: +1-915-215-5178, Fax: +1-915-545-6634, Email: mohamed.othman@ttuhsc.edu characterized by inflammation and fibrosis of both the intrahepatic and extrahepatic bile ducts ${ }^{2}$ leading to the formation of multifocal bile duct strictures. PSC is an immune-mediated, progressive disorder that will eventually develop into cirrhosis, portal hypertension, and hepatic decompensation in the majority of patients. ${ }^{3}$ In contrast, the disease variant small duct PSC presents with typical cholestatic and histological features of PSC but with normal bile ducts on cholangiography. ${ }^{4}$ PSC overlaps diagnostically with many conditions that have features of both PSC and other immune-mediated liver diseases, including autoimmune hepatitis and autoimmune pancreatitis. ${ }^{5}$ Secondary sclerosing cholangitis (SSC) is characterized by a similar multifocal biliary stricturing process, but is due to identifiable causes such as long-term biliary obstruction, infection, or inflammation, leading to the destruction of bile ducts and secondary biliarycholangitis. ${ }^{6}$ Immunoglobulin G4 (IgG4)positive sclerosing cholangitis might represent a separate entity from PSC. ${ }^{7}$

PSC is a potentially fatal disease with a poor prognosis and without an effective medical therapy. This article will summarize the challenges associated with the diagnosis and therapy of PSC and its complications.

\section{Pathogenesis}

The etiology and pathogenesis of PSC raise many unresolved questions, and PSC remains a scientific and clinical challenge to many experts. There is evidence supporting a genetic predisposition theory for PSC since PSC exhibits obvious familial and geographic clustering patterns with higher prevalence in Northern Europe (e.g. Norway, Sweden) and North America compared to Southern Europe and Asia. ${ }^{8}$ Many experts suggest that a combination of genetic and environmental factors are required for the development of PSC (e.g. vitamin D deficiency). ${ }^{9}$ The proportion and number of CD8+ T cells in the peripheral blood are decreased, and the CD4/CD8 ratio is increased in patients with autoimmune diseases, such as PSC. ${ }^{10}$ It has been proposed that deprivation of sunlight and vitamin $D$ aggravates the genetically determined CD8+ $T$ cell deficiency, thereby contributing to the high prevalence of autoimmune diseases. ${ }^{11}$ Recently, the rs738409 variant (I148 polymorphism), encoding an isoleucine-to-methionine substitution at position 148 in the adiponutrin/ palatin-like phospholipase-3(PNPLA3) gene, ${ }^{12}$ was identified as a male sex-specific disease modifier in patients with PSC and bile duct stenosis that impacted the disease course of PSC. Rs738409 is a missense variation (I148M) in PNPLA3. ${ }^{13}$ In a prospective cohort study of 468 German and Norwegian PSC 
Saadi M. et al: Primary Sclerosing Cholangitis Challenges

patients, I148 polymorphism was associated with decreased survival in male patients with severe PSC and bile duct stenosis requiring endoscopic intervention. ${ }^{14}$ The association between PSC and inflammatory bowel disease (IBD) suggested that a common genetic agent or inflammatory pathway is possibly involved in the pathogenesis of both diseases. Some experts believe that the "leaky gut hypothesis" could explain this close link. An inflamed gut with concomitant induction of an inflammatory reaction concentrated in the portal region can lead to increased intestinal permeability with bacterial translocation into the portal venous system. ${ }^{15}$ Bacteria penetrate the damaged colonic mucosal layer during the acute inflammatory response, enter the liver, and stimulate the release of inflammatory mediators like chemokines/cytokines by Kupffer cells and macrophages. This can lead to cholangitis resulting in a wound healing process with subsequent concentric periductal fibrosis. ${ }^{15,16}$ Many studies hypothesize that in genetically susceptible individuals, bacterial antigens can trigger this immune reaction that is responsible for the development of PSC. However, these studies do not reveal any direct clinical evidence for increased portal vein bacteremia in PSC/IBD patients. ${ }^{17,18}$ Clinical trials which utilized antibiotics, ${ }^{19,20}$ or antibiotics in combination with ursodeoxycholic acid, for the treatment of PSC demonstrated improved liver function tests but no effect on disease progression. ${ }^{21}$ Future studies are needed to determine if gut microbiome plays a role in the pathogenesis of PSC.

The presence of various autoantibodies, including perinuclear antineutrophil cytoplasmic antibodies ( $p$-ANCA) or antinuclear antibodies (ANA), in a patient's serum with PSC supports a role for autoimmunity in the pathogenesis of $\mathrm{PSC}^{22}$ In general, there are two distinct staining patterns of ANCA, cytoplasmic (c-ANCA) and perinuclear ( $p-A N C A)$. $P$-ANCA can be further subdivided into so-called classical p-ANCA or atypical p-ANCA. Atypical p-ANCA appears to be specific for PSC with predominant IgG classes of antibodies (in more than $80 \%$ of PSC patients). ${ }^{23}$ Due to the overlap with autoimmune hepatitis ${ }^{24}$ and the lack of correlation with PSC activity, p-ANCA has a limited clinical value in PSC diagnosis. The identity of the specific autoantigen that causes atypical $\mathrm{p}$-ANCA staining in PSC remains to be determined by future research.

\section{Diagnosis}

\section{Clinical features}

Although approximately $15 \%$ to $55 \%$ of PSC patients are asymptomatic, ${ }^{25,26}$ they are at increased risk for developing symptoms over time. ${ }^{27}$ The clinical presentation is variable; typical symptoms include right upper quadrant abdominal discomfort, fatigue, pruritus, and weight loss. ${ }^{28}$ The most frequent abnormal physical exam findings are jaundice, hepatomegaly, and splenomegaly. Episodes of cholangitis (i.e. fever and chills) are infrequent features at initial presentation of PSC, especially in the absence of prior biliary surgery or instrumentation, such as ERCP. The diagnosis of PSC is typically made when incidental findings of persistent abnormal cholestatic liver function test are investigated. Approximately $60 \%$ to $80 \%$ of patients with PSC have concomitant IBD, most often ulcerative colitis (UC). ${ }^{29}$ Table 1 describes the prevalence of symptoms in several PSC studies.
Table 1. Prevalence of PSC symptoms

\begin{tabular}{ll}
\hline Symptoms & Frequency \% \\
\hline None & $\mathbf{1 5 - 5 5}$ \\
Fatigue & $50-75$ \\
Pruritus & $40-70$ \\
Jaundice & $9-69$ \\
Abdominal pain & $16-60$ \\
Weight loss & $10-34$ \\
Fevers and chills & $5-28$ \\
\hline
\end{tabular}

\section{Serum biochemical features:}

Elevation of alkaline phosphatase is the most common biochemical abnormality and the hallmark of PSC. ${ }^{3}$ However, normal alkaline phosphatase activity does not exclude the diagnosis. Aminotransferase levels are also elevated in most patients, usually two to three times above the upper limit of the normal range. Although bilirubin levels are normal at diagnosis, an elevated total bilirubin is worrisome for advanced disease, superimposed choledocholithiasis, or malignancy. There is no significant difference between serum biochemistry profiles reported for asymptomatic and symptomatic patients. Normal albumin and prothrombin time, which reflect preserved hepatic synthetic function, are found in the majority of cases. ${ }^{3,30}$

\section{Serum serological features:}

Testing for specific autoimmune antibodies is not helpful in the diagnosis of PSC, as multiple autoantibodies can be detected. Table 2 shows the prevalence of different autoantibodies in PSC patients. Elevations in IgG and IgM are observed in $45 \%$ to $80 \%$ of the cases. Antinuclear antibody and smooth muscle antibody can be found in $20 \%$ to $50 \%$ of cases, respectively. ${ }^{22}$ Antimitochondrial antibodies are rarely found in PSC patients. The clinical significance of antibodies to biliary and colonic antigens in patients with PSC and IBD is still unclear. ${ }^{31,32}$ Perinuclear antineutrophilic antibodies are detected in frequencies ranging from $30 \%$ to $80 \%$ but lack diagnostic specificity for PSC. The antisaccharomyces cerevisiae antibody occurs in $50 \%$ of cases independent of IBD status. ${ }^{33}$

\section{Radiological modalities:}

Transabdominal ultrasound (US) can identify bile duct wall thickening and/or focal bile duct dilatations but is usually

Table 2. Serum Autoantibodies in PSC

\begin{tabular}{ll}
\hline Type of antibody & Prevalence \\
\hline Anti-neutrophil cytoplasmic antibody & $50-80 \%$ \\
Anti-nuclear antibody & $7-77 \%$ \\
Anti-smooth muscle antibody & $13-20 \%$ \\
Anti-endothelial cell antibody & $35 \%$ \\
Anti-cardiolipin antibody & $7-16 \%$ \\
Thyroglobulin & $4 \%$ \\
Rheumatoid factor & $15 \%$ \\
\hline
\end{tabular}


non-diagnostic and may be normal in PSC. One study reported that up to $41 \%$ of patients with PSC who underwent US examinations had some abnormal findings, such as wall thickening, gallbladder enlargement, ${ }^{34}$ gallstones, cholecystitis, or mass lesions. ${ }^{35}$

The findings on computed tomography (CT) crosssectional or coronal imaging of the upper abdomen are nonspecific. CT imaging with contrast enhancement can detect thickening of the bile ducts consistent with inflammation, saccular dilatations of the intrahepatic ducts, or heterogeneous bile duct dilatation. Additionally, CT can document the presence of any mass lesions or stigmata of portal hypertension, such as varices, splenomegaly, and ascites. ${ }^{36,37}$ Abdominal lymphadenopathy is a common finding in PSC and should not be over interpreted as metastases or a lymphoproliferative disorder. ${ }^{37}$

Magnetic resonance cholangiography (MRC) is considered to be the "gold standard" for the non-invasive diagnosis of PSC and is the imaging modality of choice when PSC is suspected. It is a non-invasive test, and radiation exposure can be avoided. Characteristic cholangiographic findings include multifocal, short, annular strictures that alternate with normal or slightly dilated segments producing a "beaded" pattern. Segmental fibrosis of bile ducts with saccular dilatation of normal intervening areas results in the characteristic "beads-on-a-string" appearance identified in PSC patients. Long confluent strictures may also be observed, although these are concerning for the development of superimposed cholangiocarcinoma (CCA). Intrahepatic and extrahepatic duct involvement is universal in nearly all PSC patients.

\section{Endoscopic modalities:}

Endoscopic retrograde cholangiography (ERC) has been traditionally used in the diagnosis of PSC. ERC and MRC have comparable diagnostic accuracy, although the visualization of bile ducts with MRC may be less than optimal for certain patients. Despite the high sensitivity and specificity of MRC in the diagnosis of PSC ( $80 \%$ and $87 \%$ respectively), some patients with early changes of PSC may be missed by MRC. ERC has a significant role in excluding small duct PSC, whereas MRC may not be effective. It is worth mentioning that ERC is an invasive procedure that can be associated with potentially serious complications such as pancreatitis, and in rare cases, bacterial cholangitis. ${ }^{38}$ During ERC, a detailed cholangiographic examination of the extrahepatic and intrahepatic biliary tree needs to be performed in order to establish a diagnosis of large duct PSC. In a majority of cases, both the intrahepatic and extrahepatic bile ducts are involved. In $25 \%$ of patients, the disease only involves the intrahepatic ducts; rarely ( $5 \%$ of patients) the disease is limited to the extrahepatic ducts. In this case, the diagnosis should be made with adequate filling of the intrahepatic ducts in order to demonstrate PSC findings limited to the extrahepatic ducts. Occasionally, the gallbladder, cystic duct, and pancreatic duct may be involved in PSC patients as well. ${ }^{39}$

\section{Histopathological features:}

Given the accuracy of cholangiography in diagnosing PSC, a liver biopsy is only required for assessing the stage of the disease. A retrospective study of 138 patients with cholangiographic features of PSC found that obtaining a liver biopsy rarely added any useful diagnostic information. ${ }^{40}$ The characteristic pathologic feature of PSC is concentric periductal fibrosis ('onion-skinning'). This progresses to a narrowing and then an obliteration of the small bile ducts, leaving bile duct scarring, which occurs in less than $15 \%$ of patients with PSC. ${ }^{40}$ In 1978, Ludwig et al. described the histological classification of PSC in four stages; stage one is cholangitis or portal hepatitis, stage two is periportal fibrosis or periportal hepatitis, stage three is septal fibrosis, bridging necrosis, or both, and stage four is biliary cirrhosis. ${ }^{41}$ In certain circumstances, liver biopsy could add value, especially in patients with cholestasis and IBD with normal cholangiographic findings. It can also be useful when diagnosing patients with small duct PSC with chronic cholestatic disease who present with very high transaminase levels and hypergammaglobulinemia.

\section{Other diseases that can mimic PSC:}

Table $3^{42,43}$ highlights the differential diagnoses and variant syndromes of PSC.

\section{Management of PSC and its complications}

\section{Medical treatment}

Different forms of pharmacotherapy have been evaluated for PSC treatment. Unfortunately, no medical treatment for PSC has proven efficacy in randomized controlled studies. This might be secondary to the uncertainty regarding the pathogenesis of PSC and factors responsible for its progression. ${ }^{44}$

One of the first studied pharmacologic agents for PSC was ursodeoxycholic acid (UDCA), a drug which is efficacious in treating other cholestatic liver diseases. ${ }^{44}$ UDCA is a hydrophilic, dihydroxy-bile acid which is routinely used in the treatment of primary biliary cirrhosis (PBC). UDCA has been tested alone and in combination with corticosteroids ${ }^{45}$ or other immunosuppressant agents like methotrexate, ${ }^{46}$ budesonide, azathioprine, cyclosporine, mycophenolate mofetil, ${ }^{47,48}$ oral and transdermal nicotine, ${ }^{49}$ penicillamine, ${ }^{50}$ pentoxifylline, ${ }^{50}$ silymarin, ${ }^{51}$ tacrolimus, ${ }^{52,53}$ and moexipril. ${ }^{54}$

A number of small trials using UDCA as treatment for PSC demonstrated biochemical and histological improvement with dosages of 10 to $15 \mathrm{mg} / \mathrm{kg} /$ day. ${ }^{55-57}$ A more substantial double-blinded placebo controlled trial recruited 105 patients and followed them for two to five years, using dosages of 13 to $15 \mathrm{mg} / \mathrm{kg}$ of UDCA. The results indicated improvement in serum liver tests, however, there was no improvement in symptoms and most importantly, there was no difference noted in the progression of PSC to cirrhosis. ${ }^{58}$ Higher doses of UDCA were subsequently studied on the basis that larger doses could provide sufficient enrichment of the bile acid pool in cases of cholestasis and enhance the potential immunomodulatory effect of the drug. However, the most

Table 3. Mimics of PSC

Secondary sclerosing cholangitis

Portal hypertensive biliopathy

Overlap syndrome of PSC and autoimmune hepatitis

IgG4-associated cholangitis

Ischemic-like cholangiopathy in critically ill patients 
recent systematic review, which included seven randomized control trials with a total of 553 patients, found that not only does UDCA lack a clear beneficial effect on patient survival, liver histology, prevention of CCA, and improvement of clinical symptoms, but it was actually associated with increased mortality in one of the large randomized trials. ${ }^{59-61}$

Modulation of fibrosis, especially in the histologic precirrhotic stage, is a promising treatment pathway for slowing the progression of PSC to the development of end-stage liver disease and cirrhosis. ${ }^{62}$ Pirfenidone is a known antifibrotic agent that has been investigated in 24 PSC patients. This treatment did not demonstrate any significant improvement of PSC symptoms, with more than $80 \%$ of the included patients in the study suffering from medication side effects. ${ }^{63}$ Intrabiliary rapamycin inhibited hepatic fibrosis in animal models; however, human studies are still lacking. ${ }^{64}$ Colchicine reduced mortality in primary biliary cirrhosis in one study. There is no evidence of a favorable effect of colchicine on survival, symptoms, serum biochemistry, or liver histology in patients with PSC. ${ }^{65}$

Cholestyramine, rifampicin, and opioid antagonists are proven to be effective in alleviating symptoms of pruritus in patients with PSC in several randomized trials and systematic reviews. ${ }^{66-68}$ Treatment targeted for osteoporosis and fat soluble vitamin deficiency should be also considered in patients with PSC. ${ }^{66}$

Immunosuppressive agents such as corticosteroids, etanercept, tacrolimus, cyclosporine, azathioprine, methotrexate, and infliximab are not clinically beneficial for patients with PSC. ${ }^{69,70}$ Not only have glucocorticoids been shown to be ineffective in treatment of PSC, but patients with PSC tend to have bone loss that can lead to osteoporosis that is exacerbated by glucocorticoid therapy. A study of 21 patients treated with oral budesonide found marginal improvement in serum alkaline phosphatase and AST levels. However, the Mayo Clinic Risk Score did not change significantly, and significant femoral neck bone loss was observed. ${ }^{71,72}$ Cyclosporine was shown to decrease serum alkaline phosphatase levels in treated PSC patients. However, it did not improve symptom or disease progression. ${ }^{73}$ Therapy with tacrolimus (FK506), a macrolide antibiotic with immunosuppressive activity, improved pruritus and decreased serum bilirubin and alkaline phosphatase levels by over $50 \%$. These patients, however, did not show a significant change in ERCP findings or histology. ${ }^{52}$ Immunosuppressants, therefore, have no role in the treatment of classic PSC and are not recommended. ${ }^{74,75}$ Currently, there are no medical therapies that have been proven to alter the natural course of PSC. ${ }^{76}$

\section{Endoscopic treatment:}

PSC patients are at risk for developing superimposed CCA. ${ }^{28,77-79}$ The life time risk of developing CCA in PSC patients is $10 \%$ to $15 \% .{ }^{80}$ Up to $50 \%$ of CCA cases are diagnosed simultaneously with PSC or within the first year of diagnosis of PSC, with an incident rate of $0.6 \%$ to $1.5 \%$ each year thereafter. ${ }^{78,81}$ Median survival associated with CCA is only six months. Risk factors for developing CCA in PSC patients include elevated serum bilirubin, chronic ulcerative colitis with colorectal cancer or dysplasia, variceal bleeding, proctocolectomy, and polymorphisms of the natural killer group 2, member D (NKG2D) gene (encoding a protein involved in NK cell activity)..$^{78,82,83}$ The duration of PSC may not be a risk factor for the development of CCA, which is contrary to the risk factors of neoplasia in inflammatory bowel disease. ${ }^{77}$ It is suggested that dominant strictures, defined as a common bile duct stenosis with less than $1.5 \mathrm{~mm}$ diameter remaining in the common bile duct or a common hepatic duct stenosis close to the bifurcation leaving less than $1.0 \mathrm{~mm}$ diameter of the common hepatic duct, ${ }^{84,85}$ may serve as primary indicators of concomitant CCA. ${ }^{86}$ It is very challenging to distinguish between benign strictures from PSC activity and CCA as they can have similar characteristics on imaging. Although the appearance of a mass lesion is diagnostic, mass lesions are often not present in early stages of CCA.

ERCP is widely used to evaluate dominant strictures concerning for CCA in PSC patients. When a suspicious lesion or a narrowed duct is seen during an ERCP, brush cytology can be used to obtain a tissue diagnosis. Based on numerous studies, the sensitivities of brush cytology range from $53 \%$ to $68 \%{ }^{87-89}$ with high specificity ( $97 \%$ to $100 \%$ ) in the diagnosis of CCA. ${ }^{90,91}$ Fluorescence in situ hybridization (FISH) can be added to brush cytology in order to increase its sensitivity for detecting CCA. However, FISH has a lower specificity ( $88 \%$ ) compared to brush cytology in evaluating strictures in PSC patients. ${ }^{92,93}$ Overall, FISH has been demonstrated to detect more patients with carcinoma than routine cytology and may significantly improve the chances of detecting malignancy of bile duct strictures at an early stage. ${ }^{94}$ A significant proportion of brushings was reported by pathologists as "atypical" or "suspicious for CCA". In these situations, further investigations are warranted. Recently, the Atypical Biliary Brushing Score (ABBS) has been proposed to identify those patients at high risk for malignancy in the setting of an atypical brushing. This scoring system suggested that patients with atypical brushings can be further stratified into "high risk" and "lower risk" based on a variety of factors, such as age greater than 60, presence of PSC, elevated CA 19-9 above $300 \mathrm{U} / \mathrm{ml}$, and the presence of distal CBD or hepatic duct stricture. ${ }^{95}$

Single operator cholangioscopy (SOC) has been used to evaluate indeterminate strictures in PSC. SOC gives us the ability to obtain a biopsy of an indeterminate stricture under direct visualization (Fig.1). The accuracy of SOC in detecting malignant strictures is up to $87 \% .{ }^{96}$

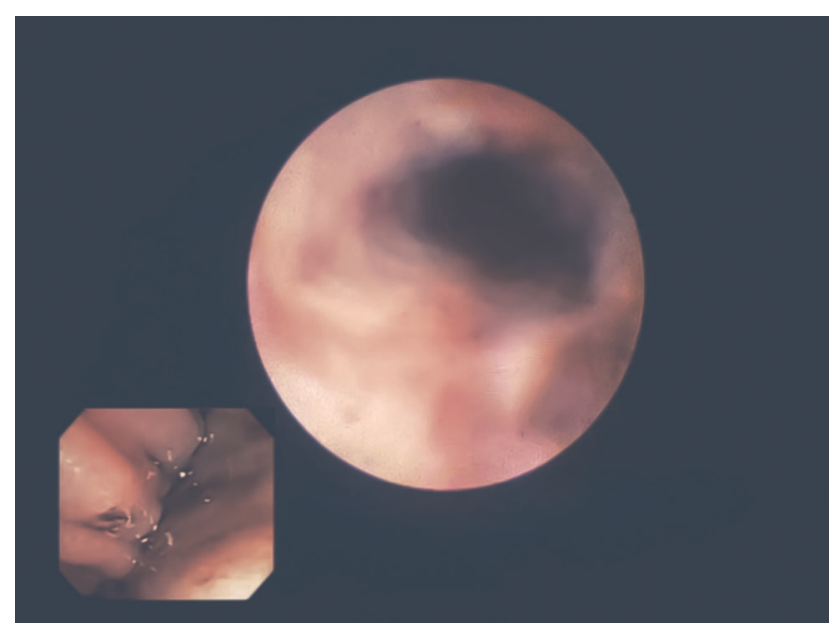

Fig. 1. CCA visualized by SOC in a dominant biliary stricture 
Probe-based confocal laser endomicroscopy (pCLE) is a new technology that allows in-vivo histologic examination of the subepithelial mucosal layer of the indeterminate biliary stricture. The use of pCLE was investigated in 15 patients with PSC and biliary strictures. The sensitivity and specificity of pCLE in differentiating benign from malignant lesions was $100 \%$ and $61 \%$, respectively. ${ }^{97}$

In cases where ERCP with cytology is inconclusive in evaluating early stage CCA, endoscopic ultrasound (EUS) emerges as an additional modality to assist in the diagnosis of CCA. The sensitivity and specificity of EUS guided fine needle aspiration (FNA) in evaluating suspicious biliary strictures in PSC ranged from $43 \%$ to $86 \%$ and $95 \%$ to $100 \%$, respectively. ${ }^{98-100}$ EUS-FNA is a promising modality for the early detection of CCA in distal strictures when ERCP with brush biopsy is not diagnostic. Sensitivity of EUS-FNA is also found to be significantly higher in detecting a distal CCA compared to a proximal malignancy ( $81 \%$ versus $59 \%){ }^{101}$ The only concerning issue with EUS-FNA is the possibility of tumor seeding. ${ }^{102}$ Although the incidence is believed to be quite rare, ${ }^{103}$ some liver transplant centers might not consider patients who have had a transmural FNA of a primary CCA as transplant candidates due to concern for possible tumor seeding.

Currently, there are no evidence-based screening guidelines for CCA in PSC. Nevertheless, endoscopic surveillance is used at various institutions to enhance early detection of CCA in patients with PSC, which has been shown to improve the chance of early resection of the tumor or liver transplant and increase survival. ${ }^{86}$

\section{Surgical treatment:}

Liver transplantation is the treatment of choice for patients with end-stage liver disease secondary to PSC. Liver transplantation should be considered in patients with PSC before the patient progresses to end-stage disease in order to enhance the long-term survival rate after liver transplantation. ${ }^{104}$ Unique liver transplant indications for patients with PSC include intractable pruritus, recurrent bacterial cholangitis, and CCA. Certain PSC patients with early stage CCA can benefit from liver transplantation. ${ }^{105}$ In the United States, patients with these unique indications are listed for liver transplantation in the regional review board appeal process established by the Liver and Intestinal Committee of United Network for Organ Sharing (UNOS). Liver transplantation for PSC is reported to have the highest patient survival rate. ${ }^{106}$ Some transplant centers report post-transplant survival rates of $90 \%$ to $97 \%$ at one year and $83 \%$ to $88 \%$ at five years. ${ }^{106,107}$ PSC liver transplant recipients may be more prone to acute and chronic cellular rejection ${ }^{108,109}$ however, with the use of immunosuppressive therapy, acute cellular rejection (ACR) is usually manageable and chronic rejection is becoming increasingly rare. The PSC recurrence rate is $20 \%$ to $25 \%$ within five to ten years after the transplant. ${ }^{108-}$ ${ }^{110} \mathrm{~A}$ history of ACR and presence of human leukocyte antigen (HLA)-DRB $1 * 08$ are associated with increased risk of recurrent PSC, suggesting an immunologic mechanism for this syndrome. ${ }^{111,112}$ The presence of CCA prior to liver transplantation is also significantly predictive of disease recurrence. ${ }^{110}$ Re-transplantation rates are reported to be higher for patients with PSC than for those with other diagnoses. ${ }^{113}$

Post-transplant management in PSC patients is the same as the management of other liver transplant recipients with two exceptions. One exception is that approximately $60 \%$ of
PSC patients with IBD have increased IBD activity after transplantation. ${ }^{114}$ The rate of proctocolectomy for intractable IBD may be increased in PSC patients following liver transplantation. ${ }^{115}$ Patients with PSC and ulcerative colitis are at increased risk for developing colonic neoplasia that persists after transplantation. ${ }^{109,116,117}$ Therefore, these patients should have an annual colonoscopy for colorectal cancer surveillance. The other exception is that PSC patients have a higher prevalence rate for metabolic bone disease. Practice guidelines recommend bone density examinations to exclude osteopenia or osteoporosis at the time of diagnosis ${ }^{118}$ and at two to three year intervals thereafter. Supplemental calcium and vitamin D, to promote calcium absorption, are also recommended in patients with a diagnosis of osteopenia. In cases of documented osteoporosis, bisphosphonates may be added. ${ }^{119}$ Bisphosphonate therapy results in significant improvement in the bone density of PBC patients, ${ }^{120}$ but it has been recently associated with jaw osteonecrosis and other problems. Thus it is now recommended for more limited use. Oral bisphosphonates have also been associated with esophageal ulcers, which could be problematic in patients with esophageal varices. In these patients, parenteral bisphosphonate therapy can be an alternative approach.

\section{Conclusions}

PSC is a chronic cholestatic liver disease that is generally progressive, and usually leads to the development of cirrhosis along with its complications. The pathogenesis of PSC remains unclear and there are currently no available medical therapies for treatment, with liver transplant representing the only available cure. Other disease-specific complications of PSC include pruritus, fatigue, vitamin deficiencies, metabolic bone disease, varices, cholangitis, biliary strictures, gallbladder stones and polyps, and malignancy, particularly CCA.

Despite the presumed autoimmune etiology of PSC, a clear benefit from immunosuppressive agents has not been established to date and their use can be limited by their side effects. Patients with PSC should be considered for therapeutic trials. Liver transplantation is currently the only lifeextending therapy, but as transplanted patients live longer, disease recurrence can be a source of morbidity and mortality. Further studies are needed to develop an optimal therapeutic strategy for patients with PSC to decrease the incidence of disease related complications, need for transplantation, and to extend the life expectancy of patients with PSC.

\section{Conflict of interest}

None

\section{Author contributions}

Writing and preparing the work presented in this paper(MS, $\mathrm{CY}, \mathrm{MOO})$, final reviewing of this article (MOO).

\section{References}

[1] Boonstra K, Beuers U, Ponsioen CY. Epidemiology of primary sclerosing cholangitis and primary biliary cirrhosis: a systematic review. J Hepatol 2012;56:1181-1188. 
[2] Maggs JR. An update on primary sclerosing cholangitis. In: RW. C, ed. Vol 24. Curr Opin Gastroenterol 2008:377-383.

[3] Tischendorf J], Hecker H, Krüger M, Manns MP, Meier PN. Characterization, outcome, and prognosis in 273 patients with primary sclerosing cholangitis: A single center study. Am J Gastroenterol 2007;102:107-114.

[4] Björnsson E, Olsson R, Bergquist A, Lindgren S, Braden B, Chapman RW, et al. The natural history of small-duct primary sclerosing cholangitis. Gastroenterology 2008;134:975-980.

[5] Gohlke F, Lohse AW, Dienes HP, Löhr H, Märker-Hermann E, Gerken G, et al. Evidence for an overlap syndrome of autoimmune hepatitis and primary sclerosing cholangitis. J Hepatol 1996;24:699-705.

[6] Abdalian R, Heathcote EJ. Sclerosing cholangitis: a focus on secondary causes. Hepatology 2006;44:1063-1074.

[7] Webster G], Pereira SP, Chapman RW. Autoimmune pancreatitis/IgG4associated cholangitis and primary sclerosing cholangitis-overlapping or separate diseases? J Hepatol 2009;51:398-402.

[8] Schrumpf E, Boberg KM. Epidemiology of primary sclerosing cholangitis. Best Pract Res Clin Gastroenterol 2001;15:553-562.

[9] Mitchell SA, Thyssen M, Orchard TR, Jewell DP, Fleming KA, Chapman RW. Cigarette smoking, appendectomy, and tonsillectomy as risk factors for the development of primary sclerosing cholangitis: a case control study. Gut 2002;51:567-573.

[10] Lindor KD, Wiesner RH, Katzmann JA, LaRusso NF, Beaver SJ. Lymphocyte subsets in primary sclerosing cholangitis. Dig Dis Sci 1987;32:720-725.

[11] Staples JA, Ponsonby AL, Lim LL, McMichael AJ. Ecologic analysis of some immune-related disorders, including type 1 diabetes, in Australia: latitude, regional ultraviolet radiation, and disease prevalence. Environ Health Perspect 2003;111:518-523.

[12] Trepo E, Pradat P, Potthoff A, Momozawa Y, Quertinmont E, Gustot T, et al. Impact of patatin-like phospholipase-3 (rs738409 C>G) polymorphism on fibrosis progression and steatosis in chronic hepatitis C. Hepatology 2011; 54:60-69.

[13] Hotta K, Yoneda M, Hyogo H, Ochi H, Mizusawa S, Ueno T, et al. Association of the rs738409 polymorphism in PNPLA3 with liver damage and the development of nonalcoholic fatty liver disease. BMC Med Genet 2010;11: 172.

[14] Friedrich K, Rupp C, Hov JR, Steinebrunner N, Weiss KH, Stiehl A, et al. A frequent PNPLA3 variant is a sex specific disease modifier in PSC patients with bile duct stenosis. PLoS One 2013;8:e58734.

[15] O'Mahony C A, Vierling J M. Etiopathogenesis of primary sclerosing cholangitis. Semin Liver Dis22006;26:3-21.

[16] Chapman R, Cullen S. Etiopathogenesis of primary sclerosing cholangitis. World J Gastroenterol 2008;14:3350-3359.

[17] Brooke BN, Dykes PW, Walker FC. A Study of Liver Disorder in Ulcerative Colitis. Postgrad Med J 1961;37:245-251.

[18] Olsson R, Björnsson E, Bäckman L, Friman S, Höckerstedt K, Kaijser B, et al. Bile duct bacterial isolates in primary sclerosing cholangitis: a study of explanted livers. J Hepatol 1998;28:426-432.

[19] Björnsson E, Cederborg A, Akvist A, Simren M, Stotzer PO, Bjarnason I. Intestinal permeability and bacterial growth of the small bowel in patients with primary sclerosing cholangitis. Scand J Gastroenterol 2005;40:10901094.

[20] Mistilis SP, Skyring AP, Goulston SJ. Effect of long-term tetracycline therapy, steroid therapy and colectomy in pericholangitis associated with ulcerative colitis. Australas Ann Med 1965;14:286-294.

[21] Färkkilä M, Karvonen AL, Nurmi H, Nuutinen $H$, Taavitsainen M, Pikkarainen $\mathrm{P}$, et al. Metronidazole and ursodeoxycholic acid for primary sclerosing cholangitis: a randomized placebo-controlled trial. Hepatology 2004;40: 1379-1386.

[22] Angulo P, Peter JB, Gershwin ME, DeSotel CK, Shoenfeld Y, Ahmed AE, et al. Serum autoantibodies in patients with primary sclerosing cholangitis. J Hepatol 2000;32:182-187.

[23] Terjung B, Spengler U. Atypical p-ANCA in PSC and AIH: a hint toward a "leaky gut"? Clin Rev Allergy Immunol 2009;36:40-51.

[24] Terjung B, Worman HJ. Anti-neutrophil antibodies in primary sclerosing cholangitis. Best Pract Res Clin Gastroenterol 2001;15:629-642.

[25] Kaplan GG, Laupland KB, Butzner D, Urbanski SJ, Lee SS. The burden of large and small duct primary sclerosing cholangitis in adults and children: a population-based analysis. Am J Gastroenterol 2007;102:1042-1049.

[26] Okolicsanyi L, Fabris L, Viaggi S, Carulli N, Podda M, Ricci G. Primary sclerosing cholangitis: clinical presentation, natural history and prognostic variables: an Italian multicentre study. The Italian PSC Study Group. Eur J Gastroenterol Hepatol 1996;8:685-691.

[27] Talwalkar JA, Lindor KD. Primary sclerosing cholangitis. Inflamm Bowel Dis 2005; 11:62-72.

[28] Broomé U, Olsson R, Lööf L, Bodemar G, Hultcrantz R, Danielsson A, et al. Natural history and prognostic factors in 305 Swedish patients with primary sclerosing cholangitis. Gut 1996;38:610-615.
[29] Wiesner RH, Grambsch PM, Dickson ER, Ludwig J, MacCarty RL, Hunter EB, et al. Primary sclerosing cholangitis: natural history, prognostic factors and survival analysis. Hepatology 1989;10:430-436.

[30] Chapman R, Fevery J, Kalloo A, Nagomey DM, Boberg KM, Shneider B, et al. Diagnosis and management of primary sclerosing cholangitis, AASLD practice guidelines. In: Fevery J, ed. Hepatology 2010;51:660-678.

[31] Boberg KM, Fausa O, Haaland T, Holter E, Mellbye OJ, Spurkland A, et al. Features of autoimmune hepatitis in primary sclerosing cholangitis: an evaluation of 114 primary sclerosing cholangitis patients according to a scoring system for the diagnosis of autoimmune hepatitis. Hepatology $1996 ; 23: 1369-1376$.

[32] Chapman RW, Cottone M, Selby WS, Shepherd HA, Sherlock S, Jewell DP. Serum autoantibodies, ulcerative colitis and primary sclerosing cholangitis. Gut 1986;27:86-91.

[33] Muratori P, Muratori L, Guidi M, Maccariello S, Pappas G, Ferrari R, et al. Anti-Saccharomyces cerevisiae antibodies (ASCA) and autoimmune liver diseases. Clin Exp Immunol 2003;132:473-476.

[34] van de Meeberg PC, Portincasa P, Wolfhagen FH, van Erpecum KJ, VanBerge-Henegouwen GP. Increased gall bladder volume in primary sclerosing cholangitis. Gut 1996;39:594-599.

[35] Said K, Glaumann H, Bergquist A. Gallbladder disease in patients with primary sclerosing cholangitis. J Hepatol 2008;48:598-605.

[36] Campbell WL, Ferris JV, Holbert BL, Thaete FL, Baron RL. Biliary tract carcinoma complicating primary sclerosing cholangitis: evaluation with $\mathrm{CT}$, cholangiography, US, and MR imaging. Radiology 1998;207:41-50.

[37] Johnson KJ, Olliff JF, Olliff SP. The presence and significance of lymphadenopathy detected by CT in primary sclerosing cholangitis. Br J Radiol 1998 $71: 1279-1282$.

[38] Ryan ME. ERCP complication rates: how low can we go? Gastrointest Endosc 2009;70:89-91.

[39] MacCarty RL, LaRusso NF, Wiesner RH, Ludwig J. Primary sclerosing cholangitis: findings on cholangiography and pancreatography. Radiology 1983;149:39-44.

[40] Burak KW, Angulo P, Lindor KD. Is there a role for liver biopsy in primary sclerosing cholangitis? Am J Gastroenterol 2003;98:1155-1158.

[41] Ludwig J, Dickson ER, McDonald GS. Staging of chronic nonsuppurative destructive cholangitis (syndrome of primary biliary cirrhosis). Virchows Arch A Pathol Anat Histol 1978;379:103-112.

[42] Gossard AA, Angulo P, Lindor KD. Secondary sclerosing cholangitis: a comparison to primary sclerosing cholangitis. Am J Gastroenterol 2005; 100:1330-1333.

[43] Björnsson E, Chari ST, Smyrk TC, Lindor K. Immunoglobulin G4 associated cholangitis: description of an emerging clinical entity based on review of the literature. Hepatology 2007;45:1547-1554.

[44] Cullen SN, Chapman RW. The medical management of primary sclerosing cholangitis. Semin Liver Dis 2006;26:52-61.

[45] Lindor KD, Wiesner RH, Colwell LJ, Steiner B, Beaver S, LaRusso NF. The combination of prednisone and colchicine in patients with primary sclerosing cholangitis. Am J Gastroenterol 1991;86:57-61.

[46] Lindor KD, Jorgensen RA, Anderson ML, Gores GJ, Hofmann AF, LaRusso NF. Ursodeoxycholic acid and methotrexate for primary sclerosing cholangitis: a pilot study. Am J Gastroenterol 1996;91:511-515.

[47] Talwalkar JA, Angulo P, Keach JC, Petz JL, Jorgensen RA, Lindor KD. Mycophenolate mofetil for the treatment of primary sclerosing cholangitis. Am J Gastroenterol 2005; 100:308-312.

[48] Sterling RK, Salvatori JJ, Luketic VA, Sanyal AJ, Fulcher AS, Stravitz RT, et al. A prospective, randomized-controlled pilot study of ursodeoxycholic acid combined with mycophenolate mofetil in the treatment of primary sclerosing cholangitis. Aliment Pharmacol Ther 2004;20:943-949.

[49] Vleggaar FP, van Buuren HR, van Berge Henegouwen GP, Hop WC, van Erpecum KJ. No beneficial effects of transdermal nicotine in patients with primary sclerosing cholangitis: results of a randomized double-blind placebo-controlled cross-over study. Eur J Gastroenterol Hepatol 2001; 13:171-175.

[50] Bharucha $A E$, Jorgensen $R$, Lichtman $S N$, LaRusso NF, Lindor KD. A pilot study of pentoxifylline for the treatment of primary sclerosing cholangitis. Am J Gastroenterol 2000;95:2338-2342.

[51] Angulo P, Jorgensen RA, Kowdley KV, Lindor KD. Silymarin in the treatment of patients with primary sclerosing cholangitis: an open-label pilot study. Dig Dis Sci 2008;53:1716-1720.

[52] Van Thiel DH, Carroll P, Abu-Elmagd K, Rodriguez-Rilo H, Irish W, McMichael J, et al. Tacrolimus (FK 506), a treatment for primary sclerosing cholangitis: results of an open-label preliminary trial. Am J Gastroenterol 1995;90:455459.

[53] Talwalkar JA, Gossard AA, Keach JC, Jorgensen RA, Petz JL, Lindor RN. Tacrolimus for the treatment of primary sclerosing cholangitis. Liver Int 2007;27:451-453.

[54] Charatcharoenwitthaya P, Talwalkar JA, Angulo P, Gossard AA, Keach JC, Petz JL, et al. Moexipril for treatment of primary biliary cirrhosis in patients 
with an incomplete response to ursodeoxycholic acid. Dig Dis Sci 2010;55: 476-483.

[55] Beuers U, Spengler U, Kruis W, Aydemir U, Wiebecke B, Heldwein W, et al. Ursodeoxycholic acid for treatment of primary sclerosing cholangitis: a placebo-controlled trial. Hepatology 1992;16:707-714.

[56] Stiehl A. Ursodeoxycholic acid therapy in treatment of primary sclerosing cholangitis. Scand J Gastroenterol 1994;204(Suppl):59-61.

[57] Chazouillères O, Poupon R, Capron JP, Metman EH, Dhumeaux D, Amouretti $M$, et al. Ursodeoxycholic acid for primary sclerosing cholangitis. J Hepatol $1990 ; 11: 120-123$.

[58] Lindor KD. Ursodiol for primary sclerosing cholangitis. Mayo Primary Sclerosing Cholangitis-Ursodeoxycholic Acid Study Group. N Engl J Med 1997;336:719-721.

[59] Othman MO, Dunkelberg J, Roy PK. Urosdeoxycholic acid in primary sclerosing cholangitis: a meta-analysis and systematic review. Arab J Gastroenterol 2012;13:103-110.

[60] Imam MH, Sinakos E, Gossard AA, Kowdley KV, Luketic VA, Edwyn Harrison $M$, et al. High-dose ursodeoxycholic acid increases risk of adverse outcomes in patients with early stage primary sclerosing cholangitis. Aliment Pharmacol Ther 2011;34:1185-1192.

[61] Lindor KD, Kowdley KV, Luketic VA, Harrison ME, McCashland T, Befeler AS, et al. High-dose ursodeoxycholic acid for the treatment of primary sclerosing cholangitis. Hepatology 2009;50:808-814.

[62] Imam MH, Lindor KD. Primary sclerosing cholangitis: providing a safe and effective treatment. Expert Rev Gastroenterol Hepatol 2012;6:255-257.

[63] Angulo P, MacCarty RL, Sylvestre PB, Jorgensen RA, Wiesner RH, LaRusso $\mathrm{NA}$, et al. Pirfenidone in the treatment of primary sclerosing cholangitis. Dig Dis Sci 2002;47:157-161.

[64] Biecker E, De Gottardi A, Neef M, Unternährer M, Schneider V, Ledermann $M$, et al. Long-term treatment of bile duct-ligated rats with rapamycin (sirolimus) significantly attenuates liver fibrosis: analysis of the underlying mechanisms. J Pharmacol Exp Ther 2005;313:952-961.

[65] Olsson R, Broomé U, Danielsson A, Hägerstrand I, Järnerot G, Lööf L, et al. Colchicine treatment of primary sclerosing cholangitis. Gastroenterology 1995; 108:1199-1203.

[66] Bunchorntavakul C, Reddy KR. Pruritus in chronic cholestatic liver disease. Clin Liver Dis 2012;16:331-346.

[67] Podesta A, Lopez P, Terg R, Villamil F, Flores D, Mastai R, et al. Treatment of pruritus of primary biliary cirrhosis with rifampin. Dig Dis Sci 1991;36:216220.

[68] Tandon P, Rowe BH, Vandermeer B, Bain VG. The efficacy and safety of bile Acid binding agents, opioid antagonists, or rifampin in the treatment of cholestasis-associated pruritus. Am J Gastroenterol 2007; 102:1528-1536.

[69] Hommes DW, Erkelens W, Ponsioen C, Stokkers P, Rauws E, van der Spek M, et al. A double-blind, placebo-controlled, randomized study of infliximab in primary sclerosing cholangitis. J Clin Gastroenterol 2008;42:522-526.

[70] Cullen SN, Chapman RW. Review article: current management of primary sclerosing cholangitis. Aliment Pharmacol Ther 2005;21:933-948.

[71] Angulo P, Batts KP, Jorgensen RA, LaRusso NA, Lindor KD. Oral budesonide in the treatment of primary sclerosing cholangitis. Am J Gastroenterol 2000;95:2333-2337.

[72] Hay JE, Lindor KD, Wiesner RH, Dickson ER, Krom RA, LaRusso NF. The metabolic bone disease of primary sclerosing cholangitis. Hepatology 1991; $14: 257-261$.

[73] Wiesner RH, Ludwig J, Lindor KD, Jorgensen RA, Baldus WP, Homburger HA, et al. A controlled trial of cyclosporine in the treatment of primary biliary cirrhosis. N Engl J Med 1990;322:1419-1424.

[74] hapman R, Fevery J, Kalloo A, Nagomey DM, Boberg KM, Shneider B, et al. Diagnosis and management of primary sclerosing cholangitis, AASLD practice guidelines, In: Fevery J, ed.Hepatology Vol. 51, No. 2, 2010.

[75] Eaton JE, Talwalkar JA, Lazaridis KN, Gores G], Lindor KD. Pathogenesis of primary sclerosing cholangitis and advances in diagnosis and management. Gastroenterology 2013;145:521-536.

[76] Singh S, Talwalkar JA. Primary sclerosing cholangitis: diagnosis, prognosis, and management. Clin Gastroenterol Hepatol 2013;11:898-907.

[77] Lazaridis KN, Gores GJ. Primary sclerosing cholangitis and cholangiocarcinoma. Semin Liver Dis 2006;26:42-51.

[78] Bergquist A, Ekbom A, Olsson R, Kornfeldt D, Lööf L, Danielsson A, et al. Hepatic and extrahepatic malignancies in primary sclerosing cholangitis. J Hepatol 2002; 36:321-327.

[79] Kornfeld D, Ekbom A, Ihre T. Is there an excess risk for colorectal cancer in patients with ulcerative colitis and concomitant primary sclerosing cholangitis? A population based study. Gut 1997;41:522-525.

[80] Gluck M, Cantone NR, Brandabur J], Patterson DJ, Bredfeldt JE, Kozarek RA. A twenty-year experience with endoscopic therapy for symptomatic primary sclerosing cholangitis. J Clin Gastroenterol 2008;42:1032-1039.

[81] Burak K, Angulo P, Pasha TM, Egan K, Petz J, Lindor KD. Incidence and risk factors for cholangiocarcinoma in primary sclerosing cholangitis. Am J Gastroenterol 2004;99:523-526.
[82] Melum E, Karlsen TH, Schrumpf E, Bergquist A, Thorsby E, Boberg KM, et al. Cholangiocarcinoma in primary sclerosing cholangitis is associated with NKG2D polymorphisms. Hepatology 2008;47:90-96.

[83] Broomé U, Löfberg R, Veress B, Eriksson LS. Primary sclerosing cholangitis and ulcerative colitis: evidence for increased neoplastic potential. Hepatology 1995;22:1404-1408.

[84] Johnson GK, Geenen JE, Venu RP, Schmalz MJ, Hogan WJ. Endoscopic treatment of biliary tract strictures in sclerosing cholangitis: a larger series and recommendations for treatment. Gastrointest Endosc 1991;37:38-43.

[85] Björnsson E, Lindqvist-Ottosson J, Asztely M, Olsson R. Dominant strictures in patients with primary sclerosing cholangitis. Am J Gastroenterol 2004; 99:502-508.

[86] Feurer M. Endoscopic Management and Therapy of Primary Sclerosing Cholangitis. Practical Gastroenterology 2013:11.

[87] PonchonT GP, Berger F. Value of endobiliary brush cytology and biopsies for the diagnosis of malignant bile duct stenosis: results of a prospective study. Gastrointest Endosc 1995;42:565-72.

[88] Pugliese V, Conio M, Nicolò G, Saccomanno S, Gatteschi B. Endoscopic retrograde forceps biopsy and brush cytology of biliary strictures: prospective study. Gastrointest Endosc 1995;42:520-526.

[89] Stewart C], Mills PR, Carter R, O'Donohue J, Fullarton G, Imrie CW, et al. Brush cytology in the assessment of pancreatico-biliary strictures: a review of 406 cases. J Clin Pathol 2001;54:449-455.

[90] Volmar KE, Vollmer RT, Routbort MJ, Creager AJ. Pancreatic and bile duct brushing cytology in 1000 cases: review of findings and comparison of preparation methods. Cancer Cytopathol 2006;108:231-238.

[91] Jailwala J, Fogel EL, Sherman S, Gottlieb K, Flueckiger J, Bucksot LG, et al. Triple-tissue sampling at ERCP in malignant biliary obstruction. Gastrointest Endosc 2000;51:383-390.

[92] Smoczynski M, Jablonska A, Matyskiel A, Lakomy J, Dubowik M, Marek $\mathrm{I}$,et al. Routine brush cytology and fluorescence in situ hybridization for assessment of pancreatobiliary strictures. Gastrointest Endosc 2012;75 65-73.

[93] Charatcharoenwitthaya P, Enders FB, Halling KC, Lindor KD. Utility of serum tumor markers, imaging, and biliary cytology for detecting cholangiocarcinoma in primary sclerosing cholangitis. Hepatology 2008;48:1106-1117.

[94] Barr Fritcher EG, Kipp BR, Voss JS, Clayton AC, Lindor KD, Halling KC, et al. Primary sclerosing cholangitis patients with serial polysomy fluorescence in situ hybridization results are at increased risk of cholangiocarcinoma. Am J Gastroenterol 2011;106:2023-2028.

[95] Witt BL, Kristen Hilden RN, Scaife C, Chadwick B, Layfield L, Cory Johnston $\mathrm{W}$, et al. Identification of factors predictive of malignancy in patients with atypical biliary brushing results obtained via ERCP. Diagn Cytopathol 2013 41:682-688.

[96] Kalaitzakis E, Webster G], Oppong KW, Kallis Y, Vlavianos P, Huggett M, et al. Diagnostic and therapeutic utility of single-operator peroral cholangioscopy for indeterminate biliary lesions and bile duct stones. Eur J Gastroenterol Hepatol 2012;24:656-664.

[97] Heif M, Yen RD, Shah RJ. ERCP with probe-based confocal laser endomicroscopy for the evaluation of dominant biliary stenoses in primary sclerosing cholangitis patients. Dig Dis Sci 2013;58:2068-2074.

[98] Eloubeidi MA, Chen VK, Jhala NC, Eltoum IE, Jhala D, Chhieng DC, et al. Endoscopic ultrasound-guided fine needle aspiration biopsy of suspected cholangiocarcinoma. Clin Gastroenterol Hepatol 2004;2:209-213.

[99] Rösch T, Hofrichter K, Frimberger E, Meining A, Born P, Weigert N, et al. ERCP or EUS for tissue diagnosis of biliary strictures? A prospective comparative study. Gastrointest Endosc 2004;60:390-396.

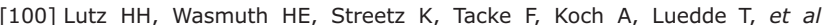
Endoscopic ultrasound as an early diagnostic tool for primary sclerosing cholangitis: a prospective pilot study. Endoscopy 2012;44:934-939.

[101] Mohamadnejad M, DeWitt JM, Sherman S, LeBlanc JK, Pitt HA, House MG, et al. Role of EUS for preoperative evaluation of cholangiocarcinoma: a large single-center experience. Gastrointest Endosc 2011;73:71-78.

[102] Early DS, Acosta RD, Chandrasekhara V, Chandrasekhara V, Chathadi KV, Decker GA, et al. Adverse events associated with EUS and EUS with FNA. Gastrointest Endosc 2013;77:839-843.

[103] Paquin SC, Gariépy G, Lepanto L, Bourdages R, Raymond G, Sahai AV. A first report of tumor seeding because of EUS-guided FNA of a pancreatic adenocarcinoma. Gastrointest Endosc 2005;61:610-611.

[104] Nashan B, Schlitt HJ, Tusch G, Oldhafer KJ, Ringe B, Wagner S, et al. Biliary malignancies in primary sclerosing cholangitis: timing for liver transplantation. Hepatology 1996;23:1105-1111.

[105] Kaya M, de Groen PC, Angulo P, Nagorney DM, Gunderson LL, Gores G], et al. Treatment of cholangiocarcinoma complicating primary sclerosing cholangitis: the Mayo Clinic experience. Am J Gastroenterol 2001;96: 1164-1169.

[106] Roberts MS, Angus DC, Bryce CL, Valenta Z, Weissfeld L. Survival after liver transplantation in the United States: a disease-specific analysis of the UNOS database. Liver Transpl 2004;10:886-897. 
[107] Merion RM. When is a patient too well and when is a patient too sick for a liver transplant? Liver Transpl 2004;10 (suppl 2):S69-73.

[108] Florman S, Schiano T, Kim L, Maman D, Levay A, Gondolesi G, et al. The incidence and significance of late acute cellular rejection ( $>1000$ days) after liver transplantation. Clin Transplant 2004;18:152-155.

[109] Graziadei IW, Wiesner RH, Marotta PJ, Porayko MK, Hay JE, Charlton MR, et al. Long-term results of patients undergoing liver transplantation for primary sclerosing cholangitis. Hepatology 1999;30:1121-1127.

[110] Campsen J, Zimmerman MA, Trotter JF, Wachs M, Bak T, Steinberg T, et al. Clinically recurrent primary sclerosing cholangitis following liver transplantation: a time course. Liver Transpl 2008;14:181-185.

[111] Fosby B, Karlsen TH, Melum E. Recurrence and rejection in liver transplantation for primary sclerosing cholangitis. World J Gastroenterol 2012;18:1-15.

[112] Alexander J, Lord JD, Yeh MM, Cuevas C, Bakthavatsalam R, Kowdley KV. Risk factors for recurrence of primary sclerosing cholangitis after liver transplantation. Liver Transpl 2008;14:138-143.

[113] LaRusso NF, Shneider BL, Black D, Gores G], James SP, Doo E, et al. Primary sclerosing cholangitis: summary of a workshop. Hepatology 2006;44:746764.

[114] Verdonk RC, Dijkstra G, Haagsma EB, Shostrom VK, Van den Berg AP, Kleibeuker $\mathrm{JH}$, et al. Inflammatory bowel disease after liver transplantation: risk factors for recurrence and de novo disease. Am J Transplant 2006;6: $1422-1429$.

[115] Dvorchik I, Subotin M, Demetris AJ, Fung JJ, Starzl TE, Wieand S, et al. Effect of liver transplantation on inflammatory bowel disease in patients with primary sclerosing cholangitis. Hepatology 2002;35:380-384.

[116] Loftus EV, Aguilar HI, Sandborn WJ, Tremaine WJ, Krom RA, Zinsmeister $\mathrm{AR}$, et al. Risk of colorectal neoplasia in patients with primary sclerosing cholangitis and ulcerative colitis following orthotopic liver transplantation. Hepatology 1998;27:685-690.

[117] Vera A, Gunson BK, Ussatoff V, Nightingale P, Candinas D, Radley S, et al. Colorectal cancer in patients with inflammatory bowel disease after liver transplantation for primary sclerosing cholangitis. Transplantation 2003; 75:1983-1988.

[118] Guichelaar MM, Kendall R, Malinchoc M, Hay JE. Bone mineral density before and after OLT: long-term follow-up and predictive factors. Liver Transpl 2006;12:1390-1402.

[119] Collier J. Bone disorders in chronic liver disease. Hepatology 2007;46: 1271-1278.

[120] Zein CO, Jorgensen RA, Clarke B, Wenger DE, Keach JC, Angulo P, et al. Alendronate improves bone mineral density in primary biliary cirrhosis: a randomized placebo-controlled trial. Hepatology 2005;42: 762-771. 